\title{
GPs' contributions to district management teams
}

\author{
SIMON JENKINS
}

One administrative innovation of the reorganisation of the National Health Service (NHS) in 1974 that many agree has proved its worth is the district management team (DMT). ${ }^{1}$ These teams have survived the 1982 reorganisation, ${ }^{2}$ and their continued successful operation is essential for the running of the NHS and planning of its future. These teams are where clinicians and administrators thrash out management decisions. But whereas the nurse, the administrator, the treasurer, and the community physician all work full time on administration in the health authorities the consultant and the general practitioner contribute their medical knowledge and "management skills" while continuing with clinical practice. To do this work, however, they have to give up some clinical responsibilities, and the amount of time they devote to DMT duties has been a matter of contention between the profession and the Department of Health and Social Security. Consultants on a DMT usually give up a session or two of clinical work, and the health authority is responsible for finding medical cover for these sessions; if they do private practice this may have to be adjusted to allow for their DMT duties. GPs, however, as independent contractors, are responsible for arranging cover for their absences from NHS practice. Whether this is done by other partners or by employing a locum the DMT GP will have to pay for this cover, so the extent to which the DHSS remuneration for DMT duties covers the real cost to the GP is bound to influence the ease with which GPs can be persuaded to do this valuable work.

In 1981 the Eleventh Report of the Review Body on Doctors' and Dentists' Remuneration said that there was insufficient evidence on the amount of work done by the clinical members of area management teams (AMTs) and DMTs for it to recommend increases in their remuneration. ${ }^{3}$ For the 1982 review the profession submitted some additional information on the work of clinical members of DMTs, pointing out, according to the Review Body, that "a clear picture of the work involved was unlikely to emerge until some time after the restructuring of the NHS." 4 The statistical evidence available to the profession suggested that consultant members spent an average of two to three hours a week attending formal meetings with rather less time spent on preparatory and follow-up work. Some GPs were reported as having been members of DMTs for more than the four-year period originally intended due to difficulties in finding replacements. In oral evidence the profession argued that both GP and consultant DMT members were inadequately reimbursed for the work and that it was proving increasingly difficult to attract good recruits. The Health Departments, however, reported that they had no firm evidence of any shortage of clinical members. The Review Body's judgment of the position is given in the box.

After the Review Body's 1981 report, and in the light of the great deal of anecdotal evidence of the time and effort that the GP members were putting into their duties, I was persuaded to survey all GPs in the North Western Regional Health Authority

Minden Medical Centre, Bury, Lancashire BL9 0QG

SIMON JENKINS, MB, FRCGP, general practitioner
(NWRHA) who had held posts on AMTs* and DMTs since the 1974 reorganisation.

Before 1 April 1982 there were nine single-district areas, one area with three districts (Manchester), and one area with six districts (Lancashire) in the RHA. There were thus six DMT posts in Lancashire, three in Manchester, and nine AMT posts in the remaining nine areas without districts. The resident population of the RHA at 1 April 1981 was 3938200 and the population of the districts varied from 311100 to 106400 .

\section{Methods and results}

Since 1974, 35 GPs had held posts on AMTs and DMTs. I wrote the following letter to all 35 in November 1981:

"In an attempt to discover just how much time AMT and DMT general practitioner members spend in the execution of their duties, I am writing to past and present holders in these posts in the north-west region. The information will be of particular interest to the General Medical Services Committee.

"I would be grateful if you would let me know the total time (approximately) that is spent by you on activities connected with your post. If possible, I would like you to break this down into the time spent in official DMT meetings; in the DMT premeetings that pre-

*With the 1982 reorganisation of the NHS area health authorities and hence AMTs were abolished.

\section{Review Body's 1982 views}

"While the evidence we have received this year on the time spent on DMT work has been helpful, we do not consider that the payment for clinical members should be entirely time-related. The evidence of a shortage of people willing to serve is inconclusive but it is clear that, of necessity, some clinical members have served for longer than was originally intended. It is important that the DMTs should not be hampered by difficulties in attracting clinical members in the period following restructuring, which both parties agree is likely to have an important but as yet uncertain effect on their work. Members or potential members should not be expected to suffer a financial penalty. We have taken these considerations into account in recommending a modest relative increase in the level of payment this year. Our recommendation has the effect of removing the link between the level of the payment and the value of our notional half day on the maximum of the consultant salary. We shall want to review the payment when there is clear evidence of the effects of NHS restructuring on the nature and level of the responsibilities entailed, and in the light of any further evidence of recruitment problems." 
cede the meetings of the authority; in reading and research for various meetings; in sitting on appointment committees; in attending the authority meetings themselves; and in meetings involving discussions with offices of other districts and areas and regions.

"I would also like to know if your concept of the nature and volume of the work has changed since you first took office. Perhaps you could indicate if you envisage any difficulty in finding a replacement when you relinquish the post.

"Do you feel that you should have a deputy general practitioner to the DMT who would ensure that the interests of the general practitioners in your district are protected during your absence on holiday etc ?"

The majority replied promptly, but a reminder was sent in January 1982 to those who had not replied.

Twenty-seven of the 35 GPs contacted replied. Of the 18 members who were currently serving, only three failed to reply to either letter. Table I shows that where doctors provided information about the number of hours a week taken up by the appointment, 23 spent on average eight and a half hours a week within a range of three and a half to 12 hours. For those GPs in post at 31 March 1982 information was provided by 15, who spent an average of eight hours a week with a range of five to 11 hours.

TABLE I-Hours spent per week on AMT/DMT work by GP members

\begin{tabular}{|c|c|c|c|c|c|c|}
\hline & \multicolumn{4}{|c|}{ Hours per week } & \multirow{2}{*}{ Total } & \multirow{2}{*}{$\begin{array}{l}\text { Average No } \\
\text { of hours } \\
\text { per week }\end{array}$} \\
\hline & Less than 4 & $4-6$ & $7-9$ & $10-12$ & & \\
\hline \multirow{2}{*}{$\begin{array}{l}\text { All GP members } \\
\text { Members in post at } \\
31 \text { March } 1982\end{array}$} & 1 & 3 & 12 & 7 & 23 & 8.5 \\
\hline & 1 & 3 & $9^{\circ}$ & 1 & 14 & $7 \cdot 5$ \\
\hline
\end{tabular}

Though the average number of years served by all doctors was three and three-quarter years and by those currently in post four and a quarter years, six doctors had served for the full eight years and were still in post on 31 March 1982 (table II). Two other doctors served for six years and one other for five years before they were replaced.

TABLE II-Number of years spent in post as GP member of $A M T / D M T$

\begin{tabular}{|c|c|c|c|c|c|c|c|c|c|c|}
\hline & \multicolumn{8}{|c|}{ Years in post } & \multirow{2}{*}{ Total } & \multirow{2}{*}{$\begin{array}{l}\text { Average No } \\
\text { of years } \\
\text { in post }\end{array}$} \\
\hline & 1 & 2 & 3 & 4 & 5 & 6 & 7 & 8 & & \\
\hline \multirow{2}{*}{$\begin{array}{l}\text { All GP members } \\
\text { Members in post at } \\
31 \text { March } 1982\end{array}$} & 1 & 12 & 6 & 7 & 1 & 2 & & 6 & 35 & 3.9 \\
\hline & 1 & 6 & 4 & 1 & & & & 6 & 18 & $4 \cdot 3$ \\
\hline
\end{tabular}

In response to the question about providing deputies for the GP members of teams several respondents thought that a deputy would help to maintain the GP advice when the principal appointee was absent. Others thought that a deputy would not be sufficiently familiar with all the subjects and would, therefore, be unable to make a useful contribution. A more practical suggestion, however, was that before a replacement for the GP member was appointed there should be a "run-in" period of six months during which time the successor could attend all meetings. This would enable him to make a useful contribution to the decisions of the team on taking up his official appointment. He would, of course, receive a suitable payment for this "run-in" time. The problem of ensuring that this income was superannuable was also referred to in the replies to the questionnaire.

One onerous task for the GP member is to serve on other committees so that he can bring a representative point of view to the discussions in the DMT. Examples of extra committees that members attended in addition to their usual weekly AMT or DMT meetings were:
Area health authority.

Premeeting briefing of chairman.

Medical executive committee.

Regional medical committee.

Appointments board for hospital practitioner grade.

Meetings with regional officers.

Meetings with various planning committees within the authority.

Various joint meetings with the AHA, local authority, community health council.

Various seminars, local and regional.

Disciplinary subcommittees.

Ad hoc meetings with officers.

Visits to AHA wards and departments.

Attendance at local medical committee or district medical committee or both.

Innumerable day-to-day contacts with other AMT/DMT members, together with consultants, GPs, and other staff working in the area/district.

Health care planning team meetings.

Area medical advisory committee meetings.

When the district general hospital was not on a central site the work of the AMT and DMT member was increased, as was his travelling time.

\section{Discussion \\ WORK OF DMT MEMBERS}

The GP and the consultant members of the teams differ from the four other members-the medical officer, administrator, treasurer, and nursing officer-because they are not line managers of the disciplines they represent. It is their joint role to provide a clinical input to the team and to ensure that any decisions taken do not adversely affect the care of patients. Their presence ensures an even-handed consideration of all the bids for resources made by the separate interests represented at this level.

The failure in the 1982 reorganisation to give district medical committees statutory powers has deprived both the consultant and the GP members of the DMT of a formal professional forum in which to resolve the occasional but important conflicting interests of the district general hospital and the community it serves.

Thus the GP member's function has become even more crucial than it was in the 1974 structure and has added to his responsibilities. To be sensitive to the views of local GPs he must take an active interest in the affairs of the LMC and be conversant with the workings of the family practitioner committee. He will be lobbied not only by hospital staff but also by individual GPs, who may be concerned about some aspects of local services for which, because of his position on the DMT, he will be deemed responsible. It is this responsibility and the many daily contacts that are omitted from the estimate of time required to undertake the task properly but that add to the interest of the job and inevitably to its burden.

Consensus management is a time-consuming activity, and the conflicts faced by the clinical members of the team have been described by Eskin. ${ }^{5}$ She refers to the special skills needed to function effectively in a team and emphasises that their development will be enhanced by appropriate training. A typical agenda of a team includes the consideration of medical matters arising from the various medical advisory committees. This is presented by the medical officer. Similarly, nursing problems and needs will be raised by the nursing officer. With the reorganisation into units any administrative problems arising from these units will fall within the purview of the district administrator to bring to the attention of the DMT. Most of these items may be of an operational nature and their solution will depend on the availability of adequate finance. The district treasurer provides this 
expert knowledge. As well as deciding on these day-to-day operational issues, the DMT will formulate the strategic plan for the district. Such strategic plans and, indeed, their capital implications must conform to regional and national guidelines, and their preparation requires discussions within the framework of the meetings referred to above.

\section{RECRUITING GP MEMBERS}

One question to which the Review Body required an answer was an assessment of the difficulty of replacing GP members of the DMT. If six out of 18 doctors have spent eight years as the GP DMT member and a further three doctors five years or more then it is not unreasonable to assume that great difficulty has been experienced in obtaining a replacement for one-third of the total posts, and some difficulty in half of them.

It could be argued that when local GPs think that the job is being done well by their representative member they may not wish to replace him if he is willing to continue. From the replies to the questionnaires, however, it seems that this is an incorrect interpretation. Furthermore, it might be supposed that as the GP became more experienced in the work he would spend longer on it as it became absorbing and as other members devolved more work to him. There is no correlation between the numbers of hours spent on DMT work and the GP's time in post, and this suggests that the newer member is finding the work onerous. It would seem reasonable, therefore, to deduce that the difficulty in finding replacement GPs is because of the burdensome nature of the job and the poor level of the reward.

\section{Conclusions}

The Twelfth Report of the Review Body stated that "our recommendation has the effect of removing the link between the level of payments and the value of one notional half day on the

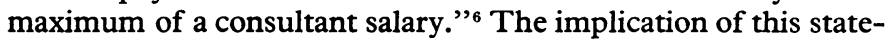
ment is that previously it was assumed that one notional half day (three and a half hours) was the necessary time required to carry out the duties. The evidence presented in this survey is that at least two notional half days is a more likely requirement, and the payment should, therefore, be more than doubled. In fact, the recommendation was to raise it from $£ 1960$ to $£ 2500$, an increase of $28 \%$ rather than the $100 \%$ requested by the profession's representatives. Furthermore, no recognition was given to the considerable extra work resulting from reorganisation.
As the Review Body recommended that the average net $\stackrel{\text { w }}{z}$ income of GPs, after allowing for expenses, should be increased $\mathbb{\Phi}$ from $£ 18480$ to $£ 19500$, a $5 \cdot 52 \%$ rise, its statement that "a $c$ modest relative increase in the level of DMT payments has been $\widehat{\partial}$ proposed" is correct. But if it has now removed the time link $\overline{\overline{5}}$ with the notional half day and set a base line well below the 7 remuneration for two notional half days I hope that the Review $\mathbb{D}$ Body will not use the 1982 recommendation as a base line to m calculate future levels of pay when the actual time spent should $\stackrel{2}{\mathrm{~V}}$ be the major factor in determining the remunerative value of the $\overrightarrow{\vec{F}}$ post.

I am concerned that the DHSS could use the statement of the Review Body "that a clear picture of the work involved was $\frac{\overline{\bar{C}}}{\bar{D}}$ unlikely to emerge until some time after the restructuring of the $\vec{\nabla}$ NHS" as an excuse for further delaying the joint national survey $\unrhd$ that is so urgently required. For this reason I believe that other $\%$ representatives of the General Medical Services Committee and $\vec{D}$ of the British Medical Association should conduct their own local surveys to provide comprehensive evidence to the Review $\vec{\omega}$ Body. The Review Body has been asking for this information for over three years. The Eleventh Report stated that "The joint examination of the nature and level of responsibilities of members of the DMT" had not got under way in time for the of 1981 review, and so the Review Body was unable to make any of recommendations in 1981. In its 1982 review the Review Body of was prevented from raising the payment to a realistic level as it had only limited additional information. Thus in the interests of $\mathrm{G}$ the profession - and, indeed, of the NHS - more facts on doctors' contributions to the work of DMTs are urgently needed.

I should like to thank Dr P J Enoch and Mr J C Ford for their help and advice in presenting these results.

\section{References}

1 Department of Health and Social Security. Management arrangements for the reorganised National Health Service. London: HMSO, 1972.

${ }^{2}$ Health Services Act 1980. London: HMSO, 1980.

3 Review Body on Doctors' and Dentists' Remuneration. Eleventh report 1981. Cmnd 8239. London: HMSO, $1981: 20$.

${ }^{4}$ Review Body on Doctors' and Dentists' Remuneration. Twelfth report 1982. Cmnd 8550. London: HMSO, 1982:13.

${ }^{5}$ Eskin F. Clinicians and management teams. Br Med $\mathcal{f}$ 1982;284:1281-2.

6 Review Body on Doctors' and Dentists' Remuneration. Twelfth report 1982. Cmnd 8550. London: HMSO, 1982:14.

(Accepted 3 November 1982)

\section{Mental Health (Amendment) Act}

The Mental Health (Amendment) Act received the Royal Assent on 28 October. The new Act, which takes effect on 30 September 1983, amends the 1959 Mental Health Act to provide better safeguards for detained patients suffering from mental disorder and clarifies the legal position of staff caring for them.

A special health authority, the Mental Health Act Commission, is to be set up to provide special safeguards for detained patients. It will give second opinionssometimes multidisciplinary ones-in certain matters affecting the treatment of patients. The commission will visit detained patients, investigate complaints, review the use of legal powers, and advise staff on good practice.

The period before detention for treatment has to be reviewed is being halved, so detained patients will have twice as many opportunities to have their case reviewed by the independent mental health review tribunal. Patients detained under the 28-day power will also be able to apply to the tribunal; long-term patients who do not apply will have an automatic review.

New rules for treating patients without their consent are being introduced. Some treatments will not be permitted without the patient's consent and an independent second opinion; some may be given without consent but only if the second opinion agrees; and others may be given for up to three months without consent or a second opinion.

Social workers will be concerned even where the nearest relative has applied for a patient's admission. Over the next two years they are to be specially trained for their work under the Act and will be called approved social workers.

More opportunities will arise through remands to hospital and interim hospital orders for hospitals and courts to test out whether a mentally disordered person appearing before the courts ought to be sent to hospital under the Act. These will be phased in gradually over the country in the next two to three years.

Voluntary patients will be able to put their names on the electoral register.

There will be a legal obligation on hospital managers to try to make sure that detained patients understand their legal status and their rights.

The Government has also said that legal $\underset{\sigma}{\sigma}$ assistance by way of representation will be made available for applicants to mental health review tribunals. 